\title{
Vasodilatory effects of cinnamaldehyde and its mechanism of action in the rat aorta
}

\author{
This article was published in the following Dove Press journal: \\ Vascular Health and Risk Management \\ 28 April 2011 \\ Number of times this article has been viewed
}

\section{Yong-Liang Xue' \\ Hai-Xia Shi' \\ Ferid Murad ${ }^{1,2}$ \\ Ka Bian ${ }^{1,2}$}

'Murad Research Institute for Modernized Chinese Medicine, Shanghai University of Traditional Chinese Medicine, Shanghai, People's

Republic of China; ${ }^{2}$ E-Institute of Shanghai Universities, Division of Nitric Oxide and Inflammatory Medicine, Shanghai,

People's Republic of China
Correspondence: Ka Bian Murad Research Center for Modernization Chinese Medicine, Shanghai University of TCM, I 200 Cailun Rd, Pudong, 20I203, Shanghai, China

Tel +86 02। 5I 322535

$\mathrm{Fax}+8602151322446$

Email kabian3@gmail.com

\begin{abstract}
The vasodilatory effect of cinnamaldehyde was investigated for its mechanism of action using isolated rings of rat aorta. Cinnamaldehyde relaxed aortic rings precontracted with phenylephrine in a dose-dependent manner, was not affected by either the presence or removal of the endothelium. Pretreatment with NG-nitro-L-arginine methyl ester and 1H-[1,2,4]-oxadiazole[4,3-a]-quinoxalin-1-one could not block vasodilation by cinnamaldehyde, indicating that nitric oxide signaling is not involved. Potassium channel blockers, such as glibenclamide, tetraethylammonium, and $\mathrm{BaCl}_{2}$, had no effect on the relaxation produced by cinnamaldehyde. In addition, treatment with either indomethacin or propranolol did not affect cinnamaldehyde-induced vasodilatation. On the other hand, pretreatment of endothelium-denuded rings with cinnamaldehyde significantly inhibited vasoconstriction induced by endogenous vasoconstrictors, including angiotensin II, 5-hydroxytryptamine, dopamine, endothelin-1, and phenylephrine. In $\mathrm{a} \mathrm{Ca}^{2+}$-free experimental setting, this natural vasodilator not only blocked $\mathrm{Ca}^{2+}$ influx-dependent vasoconstriction by either phenylephrine or $\mathrm{KCl}$, but also inhibited phenylephrine-induced tonic contraction, which relies on intracellular $\mathrm{Ca}^{2+}$ release. This study shows that endotheliumindependent, $\mathrm{Ca}^{2+}$ influx and/or an inhibitory release mechanism contributes to the vasodilatory effect of cinnamaldehyde.
\end{abstract}

Keywords: cinnamaldehyde, vasodilation, endothelium, vascular smooth muscle cell

\section{Introduction}

Cinnamomum cassia is a Chinese herbal medicine frequently used for its multiple therapeutic functions, such as enhancing immunity, eliminating the sense of coldness, relieving pain and improving blood circulation. ${ }^{1}$ In modern pharmacological research, C. cassia has exhibited diverse actions, including antioxidative stress, ${ }^{2}$ preventing mitochondrial dysfunction, ${ }^{3}$ antitumor properties, ${ }^{4}$ and inhibition of tau protein aggregation in Alzheimer's disease. ${ }^{5}$ Cinnamaldehyde, one of the main constituents of $C$. cassia, is an aromatic aldehyde which has been reported to have multiple potential therapeutic activities. ${ }^{6} \mathrm{Ma}$ et al found that cinnamaldehyde could decrease production of prostaglandin $\mathrm{E}_{2}$ stimulated by interleukin- $1 \beta$ and could downregulate the expression of transient receptor potential vanilloid subtype 4 in the cerebral microvascular endothelial cells of the mouse, which may contribute to its antipyretic effects. ${ }^{7}$ Chao et al has reported that cinnamaldehyde has antioxidant and anti-inflammatory properties. Low concentrations of cinnamaldehyde can inhibit secretion of interleukin-1 $\beta$, tumor necrosis factor $\alpha$, and reduce reactive oxygen species in lipopolysaccharide-stimulated J774 A. 1 macrophages. The phosphorylation of extracellular signal-regulated kinase $1 / 2$ and c-Jun $\mathrm{N}$-terminal kinase $1 / 2$ induced 
by lipopolysaccharides was also inhibited. ${ }^{8}$ In addition, Liao et al found that cinnamaldehyde inhibits adhesion of tumor necrosis factor $\alpha$-induced monocytes to endothelial cells, and suppresses the expression of vascular cell adhesion molecule-1 and intercellular adhesion molecule-1 at the transcriptional level by suppressing nuclear transcription factor $\kappa \mathrm{B}$ activation. ${ }^{9}$

With regard to the circulation, several studies have shown that cinnamaldehyde has antiplatelet and antithrombotic activity. ${ }^{10,11}$ In anesthetized rats, cinnamaldehyde decreased blood pressure, left ventricular systolic pressure, and rate of change of left ventricular maximum pressure (dp/dtmax). ${ }^{12}$ Cinnamaldehyde also showed a dose-dependent relaxation of the rat aorta contraction induced by noradrenaline, potassium, and prostaglandin F $2 \alpha .^{12,13}$ Based on the above observations, we hypothesized that the cardiovascular effect of cinnamaldehyde may be due to signaling beyond the receptor level. In the present study, we systematically evaluated the vasodilatory effects of cinnamaldehyde in isolated rat aorta rings using pharmacological methods and explored its potential mechanism of action.

\section{Methods and materials Reagents}

Cinnamaldehyde $\left(\mathrm{C}_{9} \mathrm{H}_{8} \mathrm{O}\right.$, Figure 1) was purchased from Aladdinbiotech Company (Shanghai, China). Acetylcholine, phenylephrine, NG-nitro-L-arginine methyl ester (L-NAME), 1H-[1,2,4]-oxadiazole-[4,3-a]-quinoxalin-1-one (ODQ), indomethacin, propranolol, glibenclamide, tetraethylammonium, $\mathrm{BaCl}_{2}$, angiotensin II, 5-hydroxytryptamine, dopamine, and endothelin-1 were purchased from Sigma Chemical Co (St Louis, MO). Ethyleneglycol bis (2-aminoethyl ether) tetra-acetic acid (EGTA) and other inorganic salts were all purchased from Sinopharm Chemical Reagent Co Ltd (Shanghai, China). Acetylcholine, phenylephrine, L-NAME, tetraethylammonium, propranolol, angiotensin II, 5-hydroxytryptamine, dopamine, and endothelin-1 were dissolved in distilled water; indomethacin, glibenclamide, and ODQ were dissolved in dimethyl sulfoxide. Control experiments had demonstrated that the highest dimethyl sulfoxide level (1:400) had no effect on vascular tone.

\section{Animals and vascular ring preparation}

Male Sprague-Dawley rats weighing 250 to $300 \mathrm{~g}$ were purchased from the Shanghai Experimental Animal Center of Academia Sinica and used for all experiments. Animals were handled and cared in compliance with the Guide for the Care and Use of Laboratory Animals (Shanghai University of Tradition Chinese Medicine).
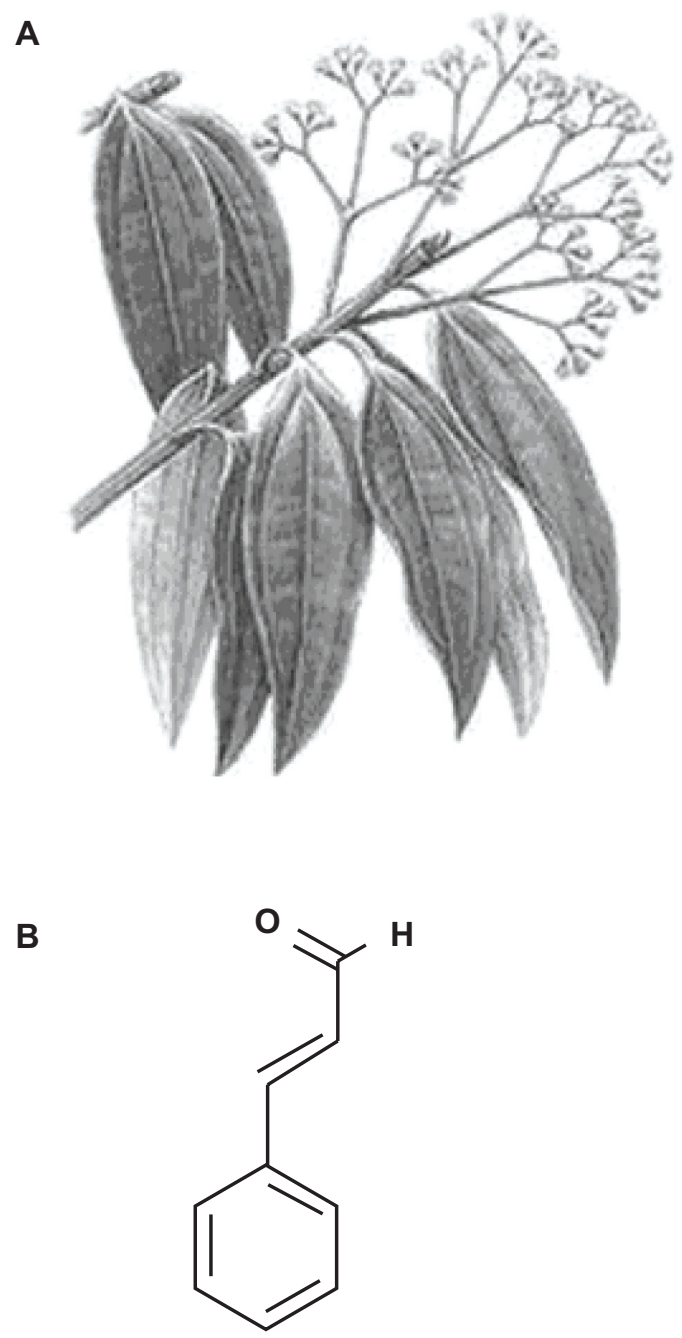

Figure I A) The Cinnamomum cassia plant. B) The chemical structure of cinnamaldehyde.

The rats were killed by cervical dislocation and their thoracic aortas were rapidly removed and dissected in ice-cold Krebs solution ( $\mathrm{pH} 7.4$, containing [mM] NaCl 118, $\mathrm{KCl} 4.7, \mathrm{MgSO}_{4}$ 1.1, $\mathrm{KH}_{2} \mathrm{PO}_{4} 1.2, \mathrm{CaCl}_{2} 1.5, \mathrm{NaHCO}_{3} 25$, and glucose 10). The aortas were cut into $3 \mathrm{~mm}$-wide ring segments after removing the surrounding connective tissue and fat. All dissection procedures were done with extreme care to protect the endothelium from inadvertent damage. In some aortic rings, the endothelial layer was mechanically removed by gently rubbing the luminal surface of the aortic ring back and forth several times with a wooden tooth pick. Each ring was suspended with two L-shaped stainless steel wires in a $4 \mathrm{~mL}$ organ bath filled with Krebs solution and maintained at $37^{\circ} \mathrm{C}$. The upper wire was connected to a force displacement transducer (Grass Instruments, West Warwick, RI) and the lower one fixed at the bottom of the organ bath. The bath solution was continuously bubbled with $95 \% \mathrm{O}_{2}$ and $5 \% \mathrm{CO}_{2}$. The baseline load placed on the aortic ring was $2.0 \mathrm{~g}$. 


\section{Examination of endothelial integrity}

At the beginning of each experiment, the bath solution was replaced every 20 minutes with prewarmed and oxygenated Krebs solution. After equilibrating for 60 minutes, all aortic rings were contracted twice with $\mathrm{KCl} 60 \mathrm{mM}$ to obtain a maximal response, and the rings were washed three times at 20-minute intervals with Krebs solution. After restoration of vessel tension to baseline levels, the rings were exposed to phenylephrine $10^{-6} \mathrm{M}$ to test their contractile responses, and subsequently challenged with acetylcholine to verify endothelial integrity or functional removal. Thus, the endothelium was considered intact when $15 \%-20 \%$ relaxation (percentage of $10^{-6} \mathrm{M}$ forskolin-evoked relaxation) was achieved by acetylcholine $10^{-7} \mathrm{M}, 60 \%$ by acetylcholine $10^{-6} \mathrm{M}$, and $>80 \%$ by acetylcholine $10^{-5} \mathrm{M}$ in aorta rings precontracted using phenylephrine. When the endothelium was fully removed, $<1 \%$ relaxation in response to acetylcholine $10^{-5} \mathrm{M}$ could be recorded (Figure 2).

\section{Vasodilation by cinnamaldehyde}

The vasodilatory effect of cinnamaldehyde was tested in both endothelium-intact and endothelium-denuded rings contracted with phenylephrine $10^{-6} \mathrm{M}$. Once a plateau of phenylephrine contraction was obtained, cinnamaldehyde was applied cumulatively at concentrations of $10^{-7}, 10^{-6}$, $10^{-5}$, and $10^{-4} \mathrm{~g} / \mathrm{mL}$. At the end of experiment, the relaxation induced by forskolin $10^{-6} \mathrm{M}$ was recorded and used as $100 \%$ for blood vessel relaxation.

To understand the mechanisms of relaxation, L-NAME (a nitric oxide synthase inhibitor) and indomethacin (a cyclo-oxygenase inhibitor) were preincubated with an endothelium-intact ring for 25 minutes, and cinnamaldehyde-induced relaxation was observed. Preparations without endothelium were pretreated for 25 minutes with

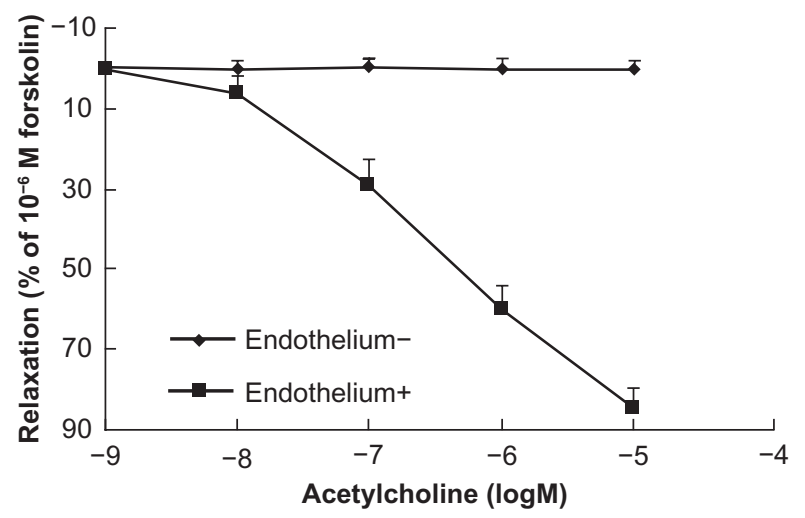

Figure 2 Concentration-response curves showing dilation by acetylcholine of endothelium-intact and endothelium-denuded rings. Acetylcholine induced endothelium-dependent relaxation at the indicated dose in phenylephrine precontracted rat aortic rings $(n=6)$.
ODQ (a soluble guanylyl cyclase inhibitor), propranolol (an adrenergic $\beta$-receptor inhibitor), glibenclamide, $\left(\mathrm{a} \mathrm{K}_{\text {ATP }}\right.$ blocker), tetraethylammonium (a $\mathrm{K}_{\mathrm{Ca}}$ blocker), and $\mathrm{BaCl}_{2}$ (a $\mathrm{K}_{\mathrm{IR}}$ blocker) prior to addition of phenylephrine $10^{-6} \mathrm{M}$. Concentration-dependent vasodilation by cinnamaldehyde was then examined.

\section{Effect of cinnamaldehyde on vasoconstriction}

The endothelium-denuded ring was first contracted in a concentration-dependent manner by a series of constrictors, including dopamine, 5-hydroxytryptamine, angiotensin II, $\mathrm{K}^{+}$, endothelin-1, and phenylephrine. After washing, the ring was incubated with cinnamaldehyde $1.3 \times 10^{-5} \mathrm{~g} / \mathrm{mL}$ or $5 \times 10^{-5} \mathrm{~g} / \mathrm{mL}$ for 10 minutes, and the contractions induced by the vasoconstrictors were again observed. The response to $60 \mathrm{mM} \mathrm{K}^{+}$was used as $100 \%$ contraction.

\section{Effect of cinnamaldehyde calcium influx}

The aorta ring without endothelium was washed and treated with $\mathrm{Ca}^{2+}$-free high- $\mathrm{K}^{+}$solution (containing $10^{-4} \mathrm{M} \mathrm{EGTA}$ and $60 \mathrm{mM} \mathrm{KCl}$ ). The $\mathrm{Ca}^{2+}$-free incubated media preparation was then cumulatively contracted with $\mathrm{CaCl}_{2}$ at concentrations in the range $0.5-3.0 \mathrm{mM}$. The contractions induced by $\mathrm{CaCl}_{2}$ were compared between the group treated with cinnamaldehyde $1.3 \times 10^{-5} \mathrm{~g} / \mathrm{mL}$ and the controls. Contraction induced by $60 \mathrm{mM} \mathrm{K}^{+}$in normal $\mathrm{Ca}^{2+}$ media was used as $100 \%$.

\section{Effect of cinnamaldehyde on calcium release}

The endothelium-denuded ring was washed and exposed to $\mathrm{Ca}^{2+}$ free Krebs solution (containing $10^{-4} \mathrm{M}$ EGTA) for 20 minutes. Phenylephrine $10^{-6} \mathrm{M}$ was added and a small tonic contraction mainly due to the release of intracellular $\mathrm{Ca}^{2+}$ was observed. Comparison between the group treated with cinnamaldehyde $1.3 \times 10^{-5} \mathrm{~g} / \mathrm{mL}$ and the controls was made, with contraction by $60 \mathrm{mM} \mathrm{K}^{+}$in normal $\mathrm{Ca}^{2+}$ media used as $100 \%$.

\section{Statistical analysis}

All data were expressed as means \pm standard error, and analyzed using one-way analysis of variance. $P<0.05$ was used as the significance level for statistical tests.

\section{Results}

\section{Cinnamaldehyde-induced relaxation}

Despite a significant difference in acetylcholine-induced relaxation in aorta ring tissue with or without endothelium (Figure 2), cinnamaldehyde relaxed the blood vessels in an 
endothelium-independent manner. Maximum relaxation of the vessel with and without endothelium by cinnamaldehyde was $86.78 \%$ and $85.71 \%$, respectively, and the $\mathrm{EC}_{50}$ was $1.16 \times 10^{-5} \mathrm{~g} / \mathrm{mL}$ and $1.32 \times 10^{-5} \mathrm{~g} / \mathrm{mL}$, respectively (Figure 3A).

To verify further the involvement of nitric oxide/cyclic guanosine monophosphate signaling pathway, we pretreated endothelium-intact aortic rings with L-NAME $10^{-4} \mathrm{M}$ or ODQ $10^{-5} \mathrm{M}$. Neither the nitric oxide synthase inhibitor nor the soluble guanylyl cyclase blocker affected cinnamaldehyde-induced vasodilation (Figures 3B and 3C).

To understand the involvement of the cyclooxygenase/ prostaglandin $\mathrm{I}_{2}$ pathway, indomethacin $10^{-5} \mathrm{M}$ was used. The relaxation curve for cinnamaldehyde was not affected by indomethacin (Figure 3B).

\section{Effect of cinnamaldehyde on potassium channels and $\beta$-receptors}

To test for possible involvement of $\mathrm{K}^{+}$channels in cinnamaldehyde-induced relaxation, we preincubated endothelium-denuded rings with tetraethylammonium
$3 \times 10^{-3} \mathrm{M}, \mathrm{BaCl}_{2} 10^{-4} \mathrm{M}$, and glibenclamide $10^{-5} \mathrm{M}$, each for 25 minutes. Tetraethylammonium (Figure 4A), $\mathrm{BaCl}_{2}$ (Figure 4B), and glibenclamide (Figure 4C) did not inhibit vascular relaxation by cinnamaldehyde. We also used propranolol $10^{-5} \mathrm{M}$ to preincubate the endothelium-denuded rings, which did not inhibit vascular relaxation induced by cinnamaldehyde (Figure 4D).

\section{Effect of cinnamaldehyde on endogenous vasoconstrictors}

Dopamine, 5-hydroxytryptamine, angiotensin II, endothelin-1, and phenylephrine are all endogenous vasoconstrictors and play key roles in vascular tone. We wondered whether cinnamaldehyde relaxes blood vessel by blocking one of the above vasoconstrictors. We pretreated endothelium-denuded aorta rings with cinnamaldehyde at $1.3 \times 10^{-5} \mathrm{~g} / \mathrm{mL}\left(\mathrm{EC}_{50}\right.$ relaxation by cinnamaldehyde) and $5.0 \times 10^{-5} \mathrm{~g} / \mathrm{mL}$, and found that cinnamaldehyde exerted inhibitory effects on the contraction curves of dopamine (Figure 5A), 5-hydroxytryptamine (Figure 5B), angiotensin II (Figure 5C), and endothelin-1 (Figure 5D), and phenylephrine (Figure 5E).
A
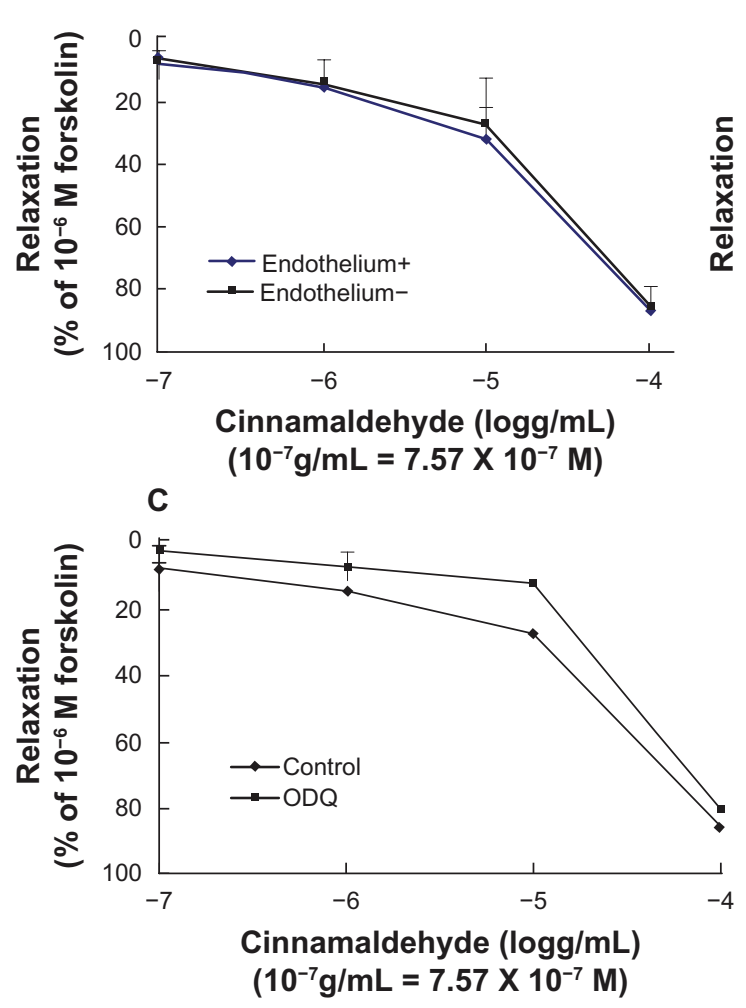

B

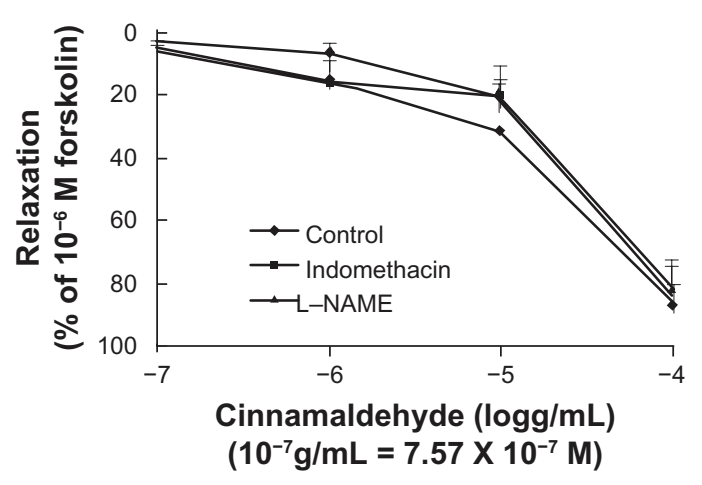

Figure 3 Dose-dependent vasodilatory effect of cinnamaldehyde on rat aorta rings. Cinnamaldehyde dilated both endothelium-intact and endothelium-denuded rings precontracted with phenylephrine, in a dose-dependent manner. The effect of cinnamaldehyde on this dilation was not different between the two groups $(\mathbf{A}$, $\mathrm{n}=6$ ). Endothelium-intact rings preincubated with NG-nitro-L-arginine methyl ester (L-NAME) $10^{-4} \mathrm{M}$ or indomethacin $10^{-5} \mathrm{M}$ did not affect cinnamaldehyde function (B, $\mathrm{n}=6$ ). Endothelium-denuded rings preincubated with IH-[I,2,4]-oxadiazole-[4,3-a]-quinoxalin-I-one (ODQ) I0 $0^{-5} \mathrm{M}$ did not inhibit the effects of cinnamaldehyde $(\mathbf{C}, \mathrm{n}=6)$. 
A

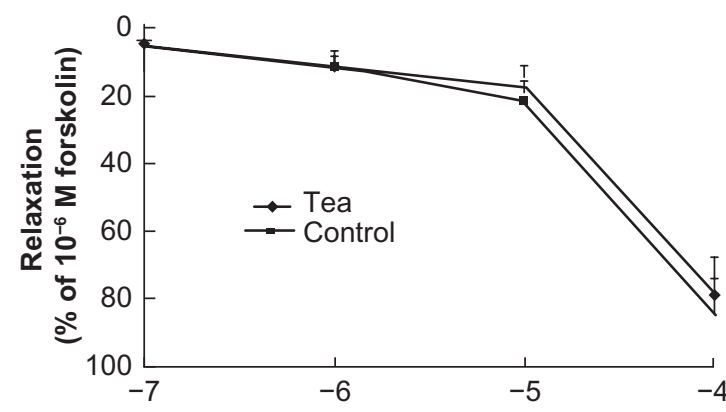

Cinnamaldehyde $(\operatorname{logg} / \mathrm{mL})\left(10^{-7} \mathrm{~g} / \mathrm{mL}=7.57 \times 10^{-7} \mathrm{M}\right)$

C

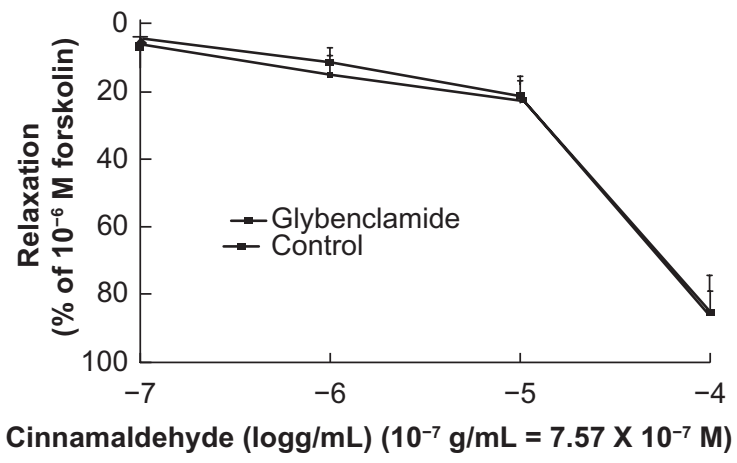

B
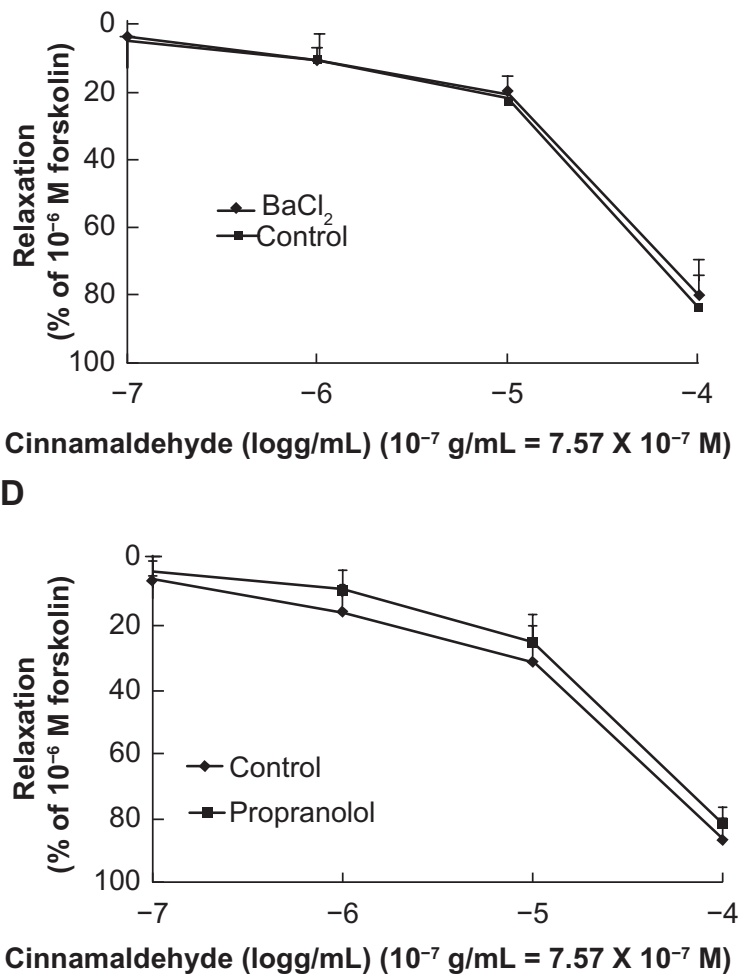

Figure 4 Effect of cinnamaldehyde on $\mathrm{K}^{+}$channels and the $\beta$-receptor. After preincubation with tetraethylammonium $3 \times 10^{-3} \mathrm{M}, \mathrm{BaCl}_{2} 10^{-4} \mathrm{M}$, or glibenclamide $10^{-5} \mathrm{M}$ for 25 minutes, the effects of cinnamaldehyde were not inhibited by tetraethylammonium $(\mathbf{A}, \mathrm{n}=6), \mathrm{BaCl}_{2}(\mathbf{B}, \mathrm{n}=6)$, or glibenclamide $(\mathbf{C}, \mathrm{n}=6)$. After preincubation with propranolol $10^{-5} \mathrm{M}$, the vasodilatory effect of cinnamaldehyde was not inhibited $(\mathbf{D}, \mathrm{n}=6)$.

\section{Effect of cinnamaldehyde on calcium influx or release}

Phenylephrine contracts vascular smooth muscle mainly by activation of receptor-operated $\mathrm{Ca}^{2+}$ channels, while $\mathrm{KC} 1$ mainly activates potential-dependent $\mathrm{Ca}^{2+}$ channels, all of which result in calcium influx. ${ }^{14}$ In this study, cinnamaldehyde pretreatment significantly reduced vasoconstriction by phenylephrine (Figure $5 \mathrm{E}$ ) and $\mathrm{KC} 1$ (Figure 6B).

To confirm the aforementioned observations, we tested the inhibitory effect of cinnamaldehyde on $\mathrm{K}^{+}$-stimulated voltage-dependent $\mathrm{Ca}^{2+}$ influx during a $\mathrm{Ca}^{2+}$-free experiment. ${ }^{14} \mathrm{As}$ demonstrated in Figure $6 \mathrm{~A}, \mathrm{Ca}^{2+}$-induced vasoconstrictions stimulated by $\mathrm{K}^{+} 60 \mathrm{mM}$ were significantly suppressed by pretreatment with cinnamaldehyde $1.3 \times 10^{-5} \mathrm{~g} / \mathrm{mL}$.

When aorta rings were exposed to $\mathrm{Ca}^{2+}$-free media, addition of phenylephrine $10^{-6} \mathrm{M}$ elicited a small tonic contraction induced mainly by intracellular $\mathrm{Ca}^{2+}$ release from endoplasmic reticulum stores. ${ }^{15}$ Pretreatment of endothelium-denuded rings with cinnamaldehyde $5.0 \times 10^{-5} \mathrm{~g} / \mathrm{mL}$ significantly reduced phenylephrine-induced contraction under extracellular $\mathrm{Ca}^{2+}$-free conditions (Figure 6C).

\section{Discussion}

Vascular endothelium plays a key role in maintaining normal function of the vasculature. ${ }^{15}$ Endothelial cells release endothelium-dependent vasodilators, such as nitric oxide and prostacyclin (prostaglandin $\mathrm{I}_{2}$ ), upon stimulation of various factors in the blood stream and as a result of physiological stress. ${ }^{15,16}$ Nitric oxide is mainly formed by nitric oxide synthase using L-arginine as a substrate. Diffusible nitric oxide gas penetrates vascular smooth muscle and activates soluble guanylyl cyclase which catalyzes guanosine triphosphate to form cyclic guanosine monophosphate. Cyclic guanosine monophosphate-activated protein kinase $\mathrm{G}$ inhibits the $\mathrm{Ca}^{2+}$ influx, reduces sensitivity of contractile elements to $\mathrm{Ca}^{2+}$, and relaxes the blood vessel. ${ }^{14}$ In our study, cinnamaldehyde-induced vasodilation was neither affected by removal of endothelium nor by treatment with L-NAME (Figure 3B) or ODQ (Figure 3C). These results suggest that the vasodilatory effect of cinnamaldehyde is not mediated through the nitric oxide/cyclic guanosine monophosphate pathway. The cyclo-oxygenase in either endothelial or smooth muscle cells can catalyze arachidonic acid to endoperoxide prostaglandin $\mathrm{H}_{2}$, which is finally 
A
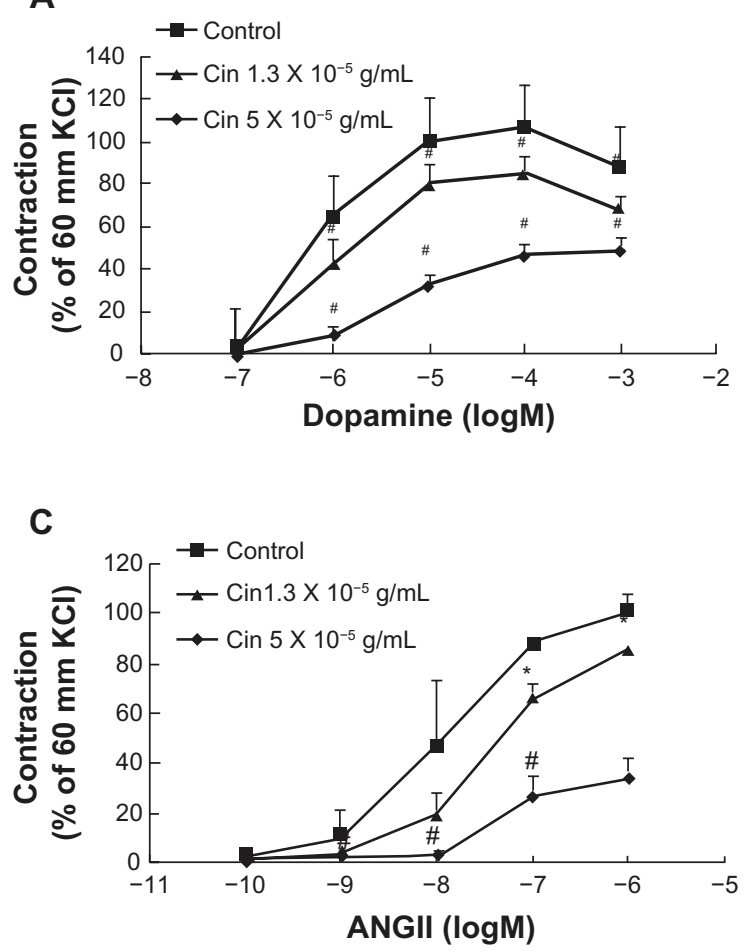

$\mathbf{E}$

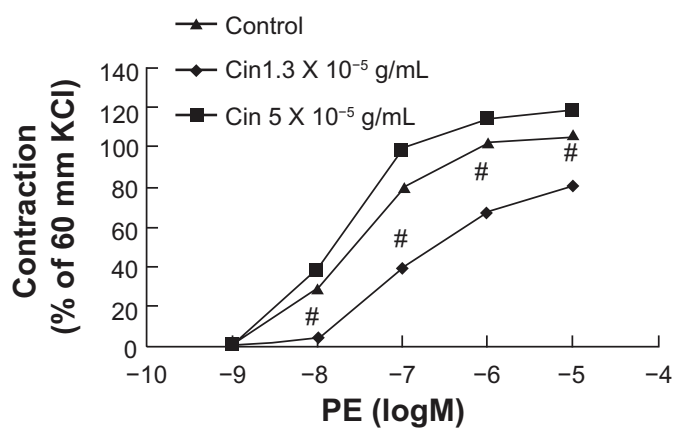

B

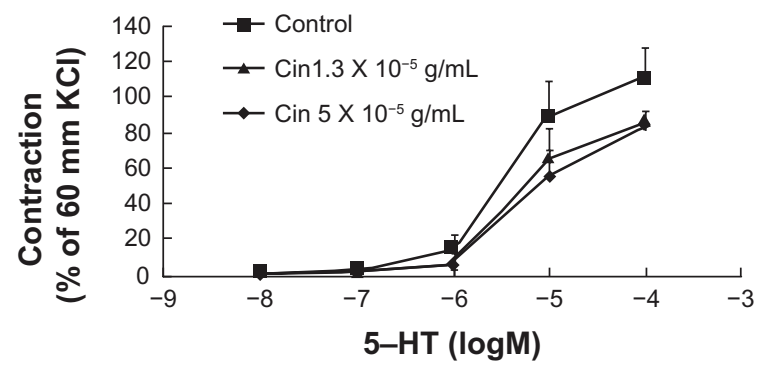

D

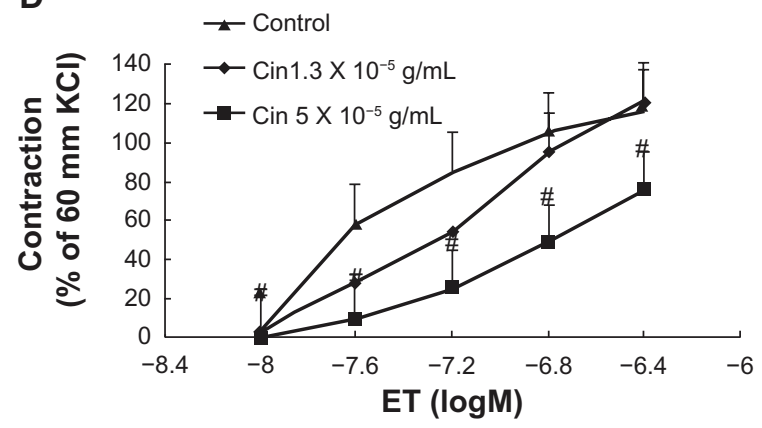

Figure 5 Concentration-response curves showing the vasoconstriction of dopamine A), 5-hydroxytryptamine B), angiotensin II C), endothelin-I D), and phenylephrine E) in the absence or presence of cinnamaldehyde ( $\mathrm{Cin}$ ). The contraction curves of all the vasoconstrictors can be inhibited by cinnamaldehyde at the indicated concentration. Notes: ${ }^{*} \mathrm{P}<0.05$ versus controls, ${ }^{*} \mathrm{P}<0.0$ I versus controls, $\mathrm{n}=6$.

converted into prostacyclin, which activates adenylyl cyclase and elevates cyclic adenosine monophosphate levels to relax the blood vessel. ${ }^{18}$ In the current study, relaxation by cinnamaldehyde in endothelium-intact aortic rings was not affected by indomethacin (Figure 3B), which rules out the involvement of the cyclo-oxygenase pathway.

Potassium channels regulate vascular smooth muscle tone by interfering with the cellular membrane potential. ${ }^{19}$ When the $\mathrm{K}^{+}$channel is activated, an efflux of $\mathrm{K}^{+}$causes membrane hyperpolarization, which reduces calcium influx and attenuates vascular tone. ${ }^{19}$ At least four types of $\mathrm{K}^{+}$channels were identified in arterial smooth muscle cells, ie, the voltagedependent $\mathrm{K}^{+}\left(\mathrm{K}_{\mathrm{v}}\right)$ channel, activated by depolarizing stimuli; the $\mathrm{Ca}^{2+}$-activated $\mathrm{K}^{+}\left(\mathrm{K}_{\mathrm{Ca}}\right)$ channel which responds to intracellular $\mathrm{Ca}^{2+}$; the inward rectifier $\mathrm{K}^{+}\left(\mathrm{K}_{\mathrm{IR}}\right)$ channel which may be responsible for external $\mathrm{K}^{+}$-induced dilation; and the adenosine triphosphate-sensitive $\mathrm{K}^{+}\left(\mathrm{K}_{\mathrm{ATP}}\right)$ channel which responds to changes in adenosine triphosphate levels. It is known that $\mathrm{Ba}^{2+}$ and tetraethylammonium antagonize a broad range of $\mathrm{K}^{+}$channels, and glibenclamide can block $\mathrm{K}_{\text {ATP }}{ }^{20}$ To test for possible involvement of $\mathrm{K}^{+}$channels in cinnamaldehyde-induced relaxation, we preincubated vessel preparations with tetraethylammonium $3 \times 10^{-3} \mathrm{M}$ (Figure 4A), $\mathrm{BaCl}_{2} 10^{-4} \mathrm{M}$ (Figure 4B), and glibenclamide $10^{-5} \mathrm{M}$ (Figure $4 \mathrm{C}$ ). We found that potassium channel blockers did not affect cinnamaldehyde-induced vasorelaxation. 
A

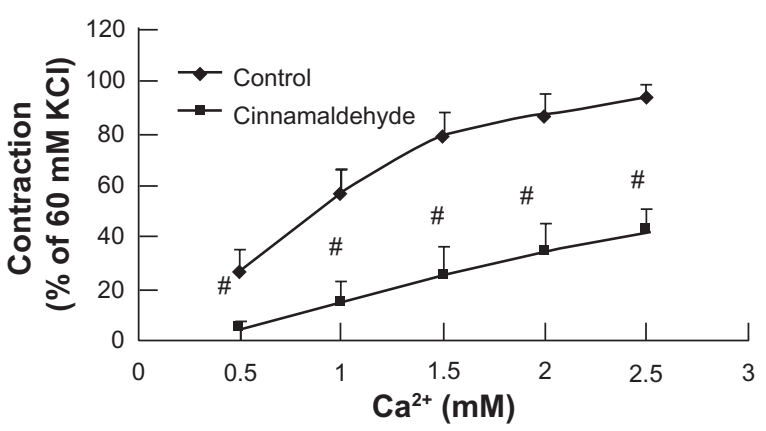

C

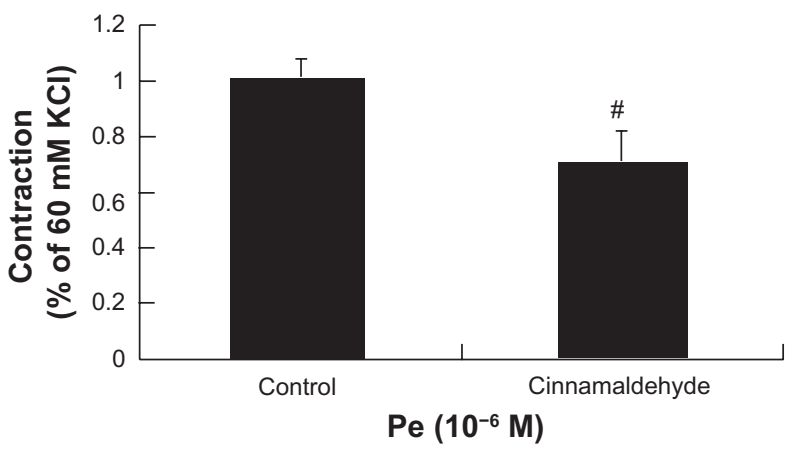

B

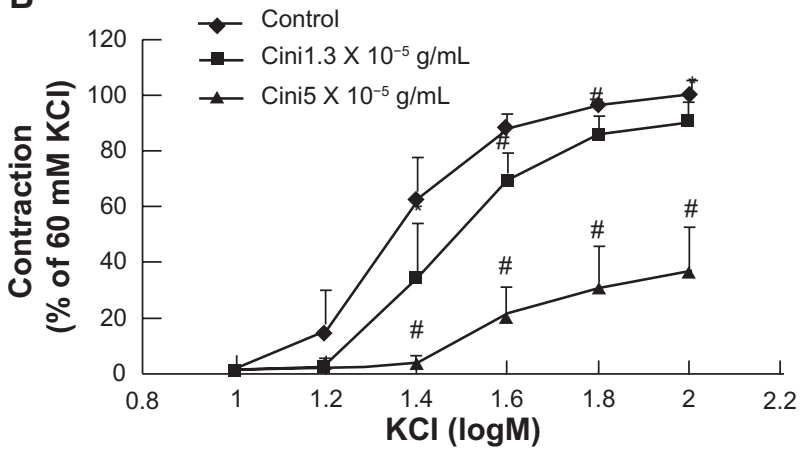

Figure 6 Effect of cinnamaldehyde on the $\mathrm{Ca}^{2+}$ channel. Rat aortic rings were preincubated with or without cinnamaldehyde for 10 minutes, and the curves of $\mathrm{CaCl}_{2}$ in $\mathrm{Ca}^{2+}$-free solution containing $10^{-4} \mathrm{M}$ EGTA and $60 \mathrm{mM} \mathrm{KCl}$ were inhibited by cinnamaldehyde $(\mathbf{A}$, $\#<0.01$ versus controls, $\mathrm{n}=6)$. Comparison of contraction percentage between the cinnamaldehyde-preincubated and control groups on cumulative concentration-response curves of $\mathrm{KCl}$. The constriction curve of $\mathrm{KCl}$ was inhibited by cinnamaldehyde (B, $* P<0.05$ versus control, ${ }^{*} P<0.01$ versus control, $\mathrm{n}=6$ ). Effect of cinnamaldehyde on the transient contraction effect of phenylephrine in $\mathrm{Ca}^{2+}$-free solution containing $10^{-4} \mathrm{M}$ EGTA. With cinnamaldehyde preincubation for 10 minutes, the contraction effect of phenylephrine in Ca ${ }^{2+}$-free solution was inhibited by cinnamaldehyde (C, ${ }^{\#}<0.01$ versus controls, $\left.\mathrm{n}=6\right)$.

The adrenergic $\beta$-receptor is an important contributor to vasodilation by increasing intracellular cyclic adenosine monophosphate and activating protein kinase $\mathrm{A} .{ }^{21}$ However, in our study, propranolol $10^{-5} \mathrm{M}$ had no effect on cinnamaldehyde (Figure 4D), suggesting that vasodilation is not mediated via the adrenergic $\beta$-receptor.

Endogenous vasoconstrictors not only play a key role in maintaining vascular tension, but also serve as therapeutic targets in many pathological conditions, such as hypertension. Blood vessels pretreated with cinnamaldehyde attenuated vasoconstriction by dopamine (Figure 5A), 5-hydroxytryptamine (Figure 5B), angiotensin II (Figure 5C), endothelin-1 (Figure 5D), and phenylephrine (Figure 5E) in a concentrationdependent manner. Thus, the involvement of a secondary signaling pathway beyond specific receptor levels is speculated. It has been shown that adrenalin, angiotensin, endothelin-1, and 5-hydroxytryptamine all have $\mathrm{G}$ protein-coupled receptors which can manipulate the intracellular $\mathrm{Ca}^{2+}$ concentration by interference with either $\mathrm{Ca}^{2+}$ influx or intracellular $\mathrm{Ca}^{2+}$ release. ${ }^{22}$ Indeed, calcium channels appear to play a crucial role in contraction of vascular smooth muscle. ${ }^{20,23}$
Intracellular $\mathrm{Ca}^{2+}$ controls smooth muscle contraction through binding with calmodulin to form a calciumcalmodulin complex. This complex further activates myosin light chain kinase to phosphorylate myosin light chains and cause muscle contraction. ${ }^{24}$ The intracellular $\mathrm{Ca}^{2+}$ concentration can be regulated by extracellular $\mathrm{Ca}^{2+}$ influx through both the voltage-dependent $\mathrm{Ca}^{2+}$ channel and the receptoroperated $\mathrm{Ca}^{2+}$ channel, or by intracellular $\mathrm{Ca}^{2+}$ release from endoplasmic reticulum $\mathrm{Ca}^{2+}$ stores. ${ }^{15} \mathrm{KCl}$ mainly activates potential-dependent $\mathrm{Ca}^{2+}$ channels to promote calcium influx and vasoconstriction. In our study, cinnamaldehyde markedly inhibited $\mathrm{CaCl}_{2}$-induced contraction of vessels treated with $\mathrm{Ca}^{2+}$-free high-K ${ }^{+}$media (Figure 6A). In addition, cinnamaldehyde also inhibited concentration-dependent contraction by $\mathrm{K}^{+}$(Figure $6 \mathrm{~B}$ ). Thus, at least, $\mathrm{Ca}^{2+}$ influx through voltagesensitive $\mathrm{Ca}^{2+}$ channels is affected by cinnamaldehyde.

On the other hand, phenylephrine regulates intracellular $\mathrm{Ca}^{2+}$ through both receptor-operated calcium channels and intracellular $\mathrm{Ca}^{2+}$ release. As showed in Figure 5E, pretreatment with cinnamaldehyde significantly reduced phenylephrine contraction, suggesting possible interference 
with $\mathrm{Ca}^{2+}$ influx through receptor-operated calcium channels. Furthermore, cinnamaldehyde also markedly inhibited small tonic contractions elicited by phenylephrine in $\mathrm{Ca}^{2+}$-free media-treated rings (Figure 6C), indicating a blockage of intracellular $\mathrm{Ca}^{2+}$ release. Taken together, we propose that cinnamaldehyde relaxes the isolated rat aorta by inhibiting both $\mathrm{Ca}^{2+}$ influx and $\mathrm{Ca}^{2+}$ release. However, further experimentation with patch clamp methods is needed to confirm this mechanism in detail.

In conclusion, the present study demonstrates that cinnamaldehyde dilates vascular smooth muscle in an endothelium-independent manner. The vasodilatory effect of cinnamaldehyde may be related to its ability to interfere with both $\mathrm{Ca}^{2+}$ influx and $\mathrm{Ca}^{2+}$ release.

\section{Acknowledgment}

This study was supported by the Shanghai Committee of Science \& Technology, E-Institutes for Nitric Oxide and Inflammatory Medicine, National Science and Technology Major Project of the Ministry of Science, and Technology of China.

\section{Disclosure}

The authors report no conflicts of interest in this work.

\section{References}

1. Teng Jia-lin T, Li Xing-Guang, Le Yin-Min. Chinese-English bilingual textbooks for international students of Chinese TCM institutions. Chinese Materia Medica. Beijing, China: People's Medical Publishing House; 2007.

2. Amin KA, Abd El-Twab TM. Oxidative markers, nitric oxide and homocysteine alteration in hypercholesterolemic rats: Role of atorvastatin and cinnamon. Int J Clin Exp Med. 2009;2(3):254-265.

3. Panickar KS, Polansky MM, Anderson RA. Cinnamon polyphenols attenuate cell swelling and mitochondrial dysfunction following oxygenglucose deprivation in glial cells. Exp Neurol. 2009;216(2):420-427.

4. Kwon HK, Jeon WK, Hwang JS, et al. Cinnamon extract suppresses tumor progression by modulating angiogenesis and the effector function of CD8+ T cells. Cancer Lett. 2009;278(2):174-182.

5. Peterson DW, George RC, Scaramozzino F, et al. Cinnamon extract inhibits tau aggregation associated with Alzheimer's disease in vitro. J Alzheimers Dis. 2009;17(3):585-597.

6. Wei RP, Huang YF, Hu DH, Zheng YG. Status and trends of researches on Cinnamomum cassia Presl. Nonwood Forest Research. 2006;24(3): 65-70.

7. MaYY, Huo HR, Li CH, et al. Effects of cinnamaldehyde on $\mathrm{PGE}^{2}$ release and TRPV4 expression in mouse cerebral microvascular endothelial cells induced by interleukin-13. Biol Pharm Bull. 2008;31(3):426-430.

Vascular Health and Risk Management

\section{Publish your work in this journal}

Vascular Health and Risk Management is an international, peerreviewed journal of therapeutics and risk management, focusing on concise rapid reporting of clinical studies on the processes involved in the maintenance of vascular health; the monitoring, prevention and treatment of vascular disease and its sequelae; and the involvement of
8. Chao LK, Hua KF, Hsu HY, et al. Cinnamaldehyde inhibits pro-inflammatory cytokine secretion from monocytes/macrophages through suppression of intracellular signaling. Food Chem Toxicol. 2008;46:220-231.

9. Liao BC, Hsieh CW, Liu YC, Tzeng TT, Sun YW, Wung BS. Cinnamaldehyde inhibits the tumor necrosis factor- $\alpha$-induced expression of cell adhesion molecules in endothelial cells by suppressing

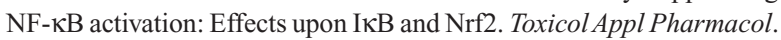
2008;292(2):161-171.

10. Huang J, Wang S, Luo X, et al. Cinnamaldehyde reduction of platelet aggregation and thrombosis in rodents. Thromb Res. 2007;119(3): 337-342.

11. Takenaga M, Hirai $A$, Terano $T$, et al. In vitro effect of cinnamic aldehyde, a main component of Cinnamomi cortex, on human platelet aggregation and arachidonic acid metabolism. J Pharmacobiodyn. 1987; 10(5):201-208.

12. Xu Ming, Yu Lu, Ding Yuan-yuan, et al. Experimental study on hypotensive effects of cinnamaldehyde in anesthetized rats. Chin Heart J. 2006;28(3):272-276.

13. Yanaga A, Goto H, Nakagawa T, et al. Cinnamaldehyde induces endothelium-dependent and -independent vasorelaxant action on isolated rat aorta. Biol Pharm Bull. 2006;29(12):2415-2418.

14. Zhang Tuan-xiao, Niu Cai-qin, Jing Hua-e, et al. Effect of water decoction of the Gastrodia elata BI on vasodilation of rabbit aorta in vitro. Journal of Clinical Rehabilitative Tissue Engineering Research. 2008;13(1):203988-203991.

15. Bian K, Toda N. Reoxygenation and calcium-induced cerebroarterial contractions as affected by vasodilator agents. J Cereb Blood Flow Metab. 1988;8(6):808-815.

16. Bian K, Doursout MF, Murad F. Vascular system: Role of nitric oxide in cardiovascular diseases. J Clin Hypertens (Greenwich). 2008;10(4): 304-310.

17. Bian K, Murad F. Nitric oxide (NO) - biogeneration, regulation, and relevance to human diseases. Front Biosci. 2003;8:d264-d278.

18. Martin W, Villani GM, JotIlianandan D. Selective blockade of endothelium-dependent and glyceryl trinitrate-induced relaxation by hemoglobin and by methylene blue in the rabbit aorta. $J$ Pharmacol Exp Ther. 1985;232(3):708-716.

19. Jia Hong-jun, Wang Zhong-ling, Yang Qi-dong. Ion Channels and Cardio-Cerebrovascular Diseases Basic Science and Clinical Practice. Beijing, China: People's Health Press; 2001.

20. Bian K, Hermsmeyer K. Glyburide actions on the dihydropyridinesensitive $\mathrm{Ca}^{2+}$ channel in rat vascular muscle. J Vasc Res. 1994;31(5): 256-264.

21. Liu ZX. Practical Cardiovascular Receptorology. Beijing, China: Science Press; 2001.

22. Berridge MJ, Bootman MD, Roderick HL. Calcium signalling: Dynamics, homeostasis and remodelling. Nat Rev Mol Cell Biol. 2003; 4(7):517-529.

23. Bian $\mathrm{K}, \mathrm{Hermsmeyer} \mathrm{K} . \mathrm{Ca}^{2+}$ channel actions of the non-dihydropyridine $\mathrm{Ca}^{2+}$ channel antagonist Ro 40-5967 in vascular muscle cells cultured from dog coronary and saphenous arteries. Naunyn Schmiedebergs Arch Pharmacol. 1993;348(2):191-196.

24. Yao T. Physiology. Beijing, China: People's Health Press; 2003.

\section{Dovepress}

metabolic disorders, particularly diabetes. This journal is indexed on PubMed Central and MedLine. The manuscript management system is completely online and includes a very quick and fair peer-review system, which is all easy to use. Visit http://www.dovepress.com/ testimonials.php to read real quotes from published authors. 